\title{
Pneumocephalus as a Cause for Headache
}

\author{
W.J. Becker
}

\begin{abstract}
Background: Pneumocephalus can be a cause of headache, but is easily overlooked in some clinical circumstances. Case Study: A 35-year-old woman developed severe headache of abrupt onset during an epidural blood patch procedure done for a post-lumbar puncture headache. A brain CT scan showed subarachnoid air even though there was no evidence of a dural puncture having occurred during the procedure. Results: The experience of our patient, and a review of the literature suggests that air injected into the epidural space during use of the "loss of resistance" technique can enter the subarachnoid space if a dural puncture site from a previous lumbar puncture is present. Conclusions: Pneumocephalus should be considered as a potential cause for a severe headache occurring in association with epidural procedures, and also in a number of other clinical settings. Use of a high inspired air oxygen concentration can hasten absorption of an intracranial air collection.
\end{abstract}

RÉSUMÉ: Le pneumo-encéphale comme cause de la céphalée. Introduction: Le pneumo-encéphale peut être une cause de céphalée, mais cette condition est ignorée dans certaines circonstances cliniques. Étude de cas: Une femme âgée de 35 ans a présenté une céphalée sévère d'apparition subite pendant un blood patch épidural effectué pour une céphalée suite à une ponction lombaire. Un CT scan cérébral a montré de l'air dans l'espace sous-arachnoïdien même s'il n'y avait pas d'indication qu'il y avait eu perforation de la dure-mère pendant la manœuvre. Résultats: L'expérience de notre patiente et une revue de la littérature suggèrent que l'air injecté dans l'espace épidural au moment de la technique de la "perte de résistance" peut pénétrer dans l'espace sous-arachnoïdien s'il existe une brèche de la dure-mère due à une ponction lombaire antérieure. Conclusions: Le pneumo-encéphale devrait être considéré comme une cause possible de céphalée sévère suite à une épidurale ainsi que dans quelques autres circonstances cliniques. L'utilisation d'air à haute concentration d'oxygène peut hâter la résorption d'une collection intracrânienne d'air.

Can. J. Neurol. Sci. 2002; 29: 278-281

Pneumoencephalography was used extensively as a diagnostic procedure in neurology prior to the advent of CT scanning, and severe headache was a well-recognised accompaniment of that procedure. Many neurologists trained in the CT/MRI era, however, may not be aware of the many clinical circumstances where pneumocephalus may be responsible for severe headache. In some cases, these headaches can be of abrupt onset, and may raise the question of whether a subarachnoid hemorrhage has occurred. Although an extensive modern literature on pneumocephalus and headache exists, this is primarily in the anaesthesia literature. With this case report and brief literature review, we hope to make neurologists more aware of pneumocephalus as a potential cause for headache in the appropriate clinical setting.

\section{Case history}

A 35-year-old woman with no significant past history of headache had an epidural anesthetic for her labour and delivery on April 1st, 1999.
The first attempt at the epidural was done at the L2-3 level, and resulted in a "wet tap" with drainage of cerebrospinal fluid (CSF) through the needle. The needle was removed, and a new insertion was done at the L3-4 level with successful administration of the epidural anesthetic.

On the next day, April 2nd, she complained of headache and neck tension when she was walking and on April 3rd the nurses again indicated that she complained of headache when sitting up. She was discharged from hospital on April 4th.

Her postural headache persisted and, on April 6th, a blood patch was done in the Emergency Department. Epidural needle placement was attempted at L4-5, but this was said to be unsuccessful, so that a second needle placement was made at L3-4. No CSF was obtained on attempted

From the University of Calgary and Calgary Health Region, Calgary, Alberta, Canada ReCEIVED JANUARY 23, 2002. ACCEPTED IN FINAL FORM APRIL 10, 2002. Reprint requests to: W J Becker, 12th Floor, Neurology, Foothills Hospital, 1403 29th Street NW, Calgary, Alberta, T2N 2T9 Canada 
aspiration and $20 \mathrm{cc}$ of autologous blood was injected, with the blood patch completed at 3:40 p.m.

When the patient rolled over after the blood patch procedure, she very quickly developed a severe headache, which was maximal frontally. At 4:30 p.m. it was noted that she found it too painful to roll onto her back. She remained on her side with an icepack applied to her forehead and felt better if she did not move. She was admitted to hospital and a patient-controlled analgesia pump was used to control her headache. That evening it was described by her as 3/10 at rest, but 10/10 on movement. There was initially no nausea, but this developed the next day, on April 7th. On April 7th, her headache was less intense, but she still had severe pain on movement. By April 9th she was much better, and she was discharged from hospital.

Her neurological examination was normal throughout her hospital stay. A brain CT scan done on April 7th (Figure), the day following the epidural blood patch procedure, showed extensive subarachnoid air. Some degree of subdural air accumulation could not be excluded.

\section{DISCUSSION}

Our patient developed a clinically typical low-pressure headache following a "wet tap" with inadvertent dural puncture during an epidural anesthetic procedure. Although it is possible that some subarachnoid air was injected at that time, the clinical description of her headaches do not support this. She showed the typical worsening with the upright posture, and improvement with recumbency characteristic of a postlumbar puncture headache.

Unfortunately, her postlumbar puncture headache did not improve, and she returned for a blood patch procedure five days later. This required two attempts before the epidural space was confidently entered, and autologous blood could be injected. There was no suggestion of a dural puncture during this procedure.

Nevertheless, the patient abruptly developed a severe bifrontal headache immediately upon changing position after the procedure. The procedure was done in the lateral position, with the patient recumbent, and it is likely, although not documented, that in attempting to roll off her side after the blood patch was completed, she elevated her head somewhat. This may have facilitated the entry of air into the cranial cavity from the spinal subarachnoid space.

The source of the subarachnoid air almost certainly included air injected as part of the "loss of resistance" technique used to identify the subarachnoid space during the two needle insertions done for the blood patch procedure. With this technique, air or saline (in this case air) is held in a syringe, and as the needle is advanced and the epidural space entered, there is a sudden loss of resistance to air injection. The low compliance of the epidural space makes this a reliable sign that the needle has left the ligamentum flavum and has entered the epidural space. ${ }^{1}$

It is difficult to measure the amount of intracranial air demonstrated by the brain CT scan in our patient, but it is potentially more than can be accounted for by the air injected directly into the epidural space during use of the "loss of resistance" technique in our patient. A second possible source for some of this air is entry of air into the epidural space through the needle while the syringe with air was exchanged for the syringe containing the blood to be used for injection. Such a mechanism has been postulated in previously reported cases of pneumocephalus. $^{2}$ The epidural space may have a negative pressure during inspiration, ${ }^{2}$ and it is possible that some air entered the epidural space and subsequently the subarachnoid space as a result of this mechanism in our patient.

How could air have entered the spinal subarachnoid space during the blood patch procedure when the subarachnoid space was apparently not violated and to the best of our knowledge no dural puncture occurred during the procedure? It appears most likely that air introduced into the spinal epidural space entered the spinal subarachnoid space through the dural puncture site which had been made five days previously when the "wet tap" occurred during her epidural anesthetic procedure and which was responsible for her low pressure headache. This appears to have been the mechanism for subarachnoid air entry in several previously reported cases. ${ }^{1,2}$
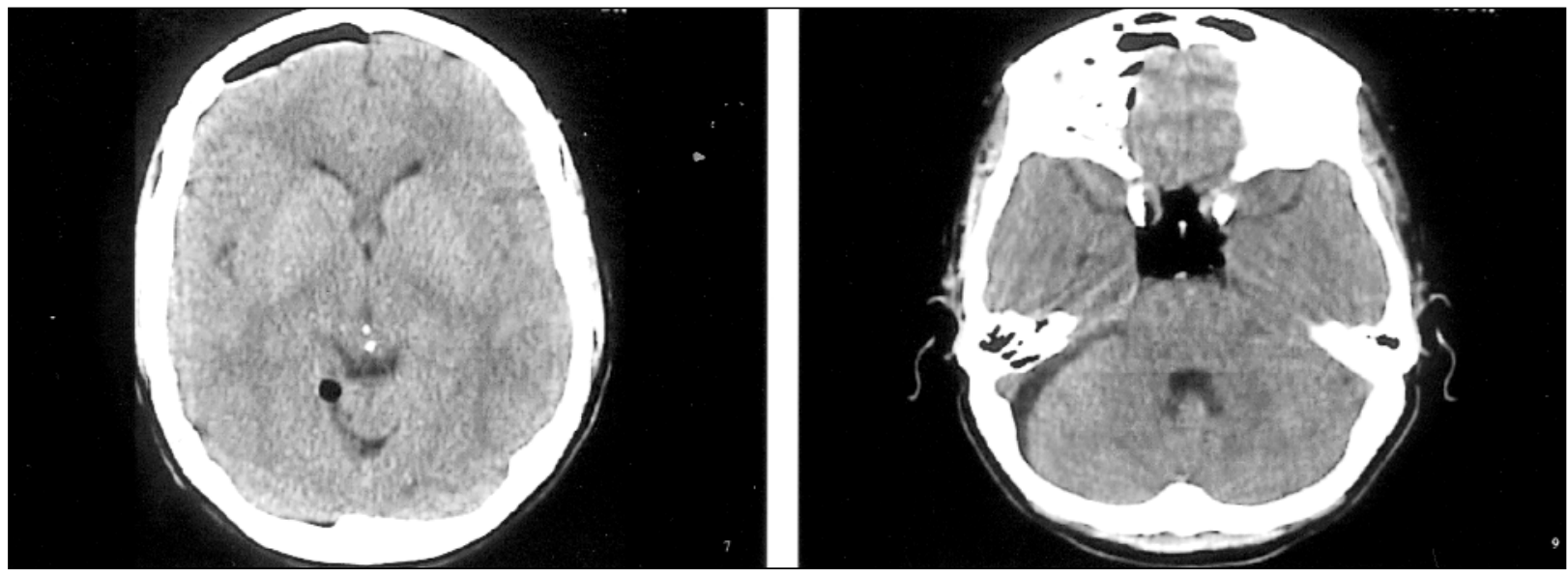

Figure: Brain CT scan without contrast enhancement done one day after the blood patch procedure. Figure 1A shows a large air collection over the right frontal lobe, and a smaller air collection in the posterior fossa. Figure $1 B$ shows a large accumulation of subarachnoid air in the suprasellar region and also over the right cerebellar hemisphere. 
The quality of the headache in our patient deserves mention. Although her initial headache prior to the blood patch was consistent with a postlumbar puncture low pressure headache as defined by the International Headache Society, ${ }^{3}$ there was an abrupt onset of a new headache immediately after the blood patch procedure. This headache was much more severe and very sensitive to movement, consistent with irritation of the meninges by intracranial air, and with the potential movement of this air with patient movement or changes in position. Of interest, several authors have stated that headache in their patients with pneumocephalus were not position dependent, but few details are given. ${ }^{4,5}$

Subarachnoid air could potentially cause significant meningeal irritation. Support for this is provided by a case report where a CSF examination was done in the first several days after injection of air into the subarachnoid space during an epidural anesthetic procedure. The CSF showed a significant inflammatory response, with 158 white cells per millilitre (with the majority lymphocytes and monocytes), elevated protein (1.17 gm/L) apparently without any associated infection. This patient did develop a transverse myelitis one month later so it is possible that other causes for CSF inflammation were present. However, she was apparently neurologically intact with no neurological symptoms at the time of the epidural, which was done for labour and delivery, and also when seen three weeks after the epidural, so it would appear that the CSF changes were secondary to subarachnoid air. ${ }^{5}$

There are two ways in which intracranial air could be introduced into the subarachnoid space during an epidural procedure without the ability to aspirate CSF during the procedure. One way would be if the air is indeed injected epidurally but is able to secondarily enter the subarachnoid space through a dural puncture site made several days previously. The blood patch procedure is a prime example where this is likely to happen, as these procedures involve an epidural penetration, and are usually done for postlumbar puncture headache.

The other mechanism could occur when the epidural needle actually punctures the dura, but fails to puncture the subarachnoid membrane. In this case, CSF cannot be aspirated, but air can still be injected subdurally. Interestingly, subdural air can very quickly enter the head, as the pressure gradient favours air movement in this direction. ${ }^{6}$ In the head, subdural air typically appears anterior to the clivus, ${ }^{6}$ but can spread widely to show accumulation subtentorially and also supratentorially over the cerebral hemispheres. ${ }^{6}$ Subdural air is said to be much more painful than subarachnoid air, with smaller volumes being able to produce severe headache. ${ }^{6}$

Although it seems clear that both subarachnoid air and subdural air can give rise to severe headache, the correlation between the presence of air and headache is less than perfect. As little as two ml of subarachnoid air has been reported to cause headache. ${ }^{7}$ However, air is absorbed only very slowly from the subarachnoid space. It has been estimated that it takes approximately six weeks to completely absorb a $50 \mathrm{ml}$ subarachnoid air collection. ${ }^{8}$ It would appear from published reports and from our patient, that at least the severe component of the headache resolves much sooner. Nevertheless, if the volume of air present and the degree of headache are at all related in the individual patient, it would seem prudent to take
Table 1: Treatment of Pneumocephalus

\begin{tabular}{ll}
\hline $\begin{array}{l}\text { Inspired Air Oxygen } \\
\text { Concentration }\end{array}$ & $\begin{array}{l}\text { Time to Absorb 50 ml of } \\
\text { Intracranial Air }\end{array}$ \\
0.21 & 5.8 weeks \\
0.4 & 1.9 weeks \\
1.0 & 0.6 weeks \\
\hline
\end{tabular}

Table 2: Causes of Pneumocephalus

Head trauma

Craniotomy

Injection of air with accidental dural puncture during epidural anesthesia ${ }^{4,9}$ blood patch procedure ${ }^{1}$ epidural saline infusions ${ }^{2}$ spinal anesthesia ${ }^{7}$

Secondary to CSF shunts ${ }^{10}$ ventriculoperitoneal shunt with bowel perforation ventriculoatrial shunt with erosion of the catheter into the lung ventriculopleural shunt with catheter erosion into the lung skull base CSF fistulas in association with CSF shunting and thinning of the cranial floor in patients with longstanding aqueductal stenosis

Secondary to CSF - pleural fistula after thoracotomy ${ }^{11}$ after spine trauma ${ }^{12}$

Nasopharyngeal carcinoma with invasion of the skull base $\mathrm{b}^{13}$

Nasal sinus surgery with perforation of the skull base ${ }^{14}$

Otogenic pneumocephalus ${ }^{15}$ with spontaneous rupture of the mastoid air cells into the intracranial cavity (i.e. during Valsalva manoeuvre) secondary to otitis media secondary to otologic surgery secondary to trauma

measures to accelerate the absorption of the intracranial air. This can best be accomplished by giving the patient a high concentration of oxygen in the inspired air. For example, it has been calculated that the time required for the complete absorption of a $50 \mathrm{ml}$ air collection can be reduced from six weeks with the patient breathing room air to two weeks if the inspired oxygen concentration is increased to $40 \%$, a level easily achievable through the use of a face mask (Table 1). Perhaps just as important, most of the air is absorbed initially with $30 \%$ of the $50 \mathrm{ml}$ collection absorbed in just two days with a $40 \%$ oxygen concentration in inspired air. ${ }^{8}$ 
Increasing inspired oxygen concentration reduces the partial pressure of nitrogen in the blood, thereby creating a greater concentration gradient for nitrogen, the main constituent of the intracranial air collection, to diffuse into the blood stream. ${ }^{8}$ In the same way, giving a patient with an intracranial air collection nitrous oxide anesthesia could at least theoretically increase the size of the air collection by diffusion of nitrous oxide from the blood into the pneumocephalus. ${ }^{9}$ It is therefore recommended that nitrous oxide general anesthesia be avoided in these patients.

The differential diagnosis of pneumocephalus is long (Table 2 ). In this respect, it is sobering to note that the first reported case of pneumocephalus was an autopsy examination in a patient who had died of ethmoiditis in $1884 .{ }^{10}$ Although head trauma and craniotomy are the most common causes of pneumocephalus, ${ }^{8,10}$ the neurologist may encounter headache secondary to pneumocephalus in a variety of clinical situations as outlined in Table 2 .

It is important that the neurologist recognise that pneumocephalus is a likely cause for a sudden headache arising during an epidural procedure. This is especially true during blood patch procedures for postlumbar puncture headache, as a dural puncture site resulting from the previous lumbar puncture can allow entry of injected air (or air drawn into the epidural space by negative pressure through an open needle) into the subarachnoid space. Utilisation of preservative-free saline rather than air for the "loss of resistance" technique for localising the epidural space might well reduce the incidence of pneumocephalus following epidural procedures. However, since the first description of epidural anesthesia in 1885, numerous methods for the identification of the epidural space have been proposed, and the "loss of resistance" technique published by Sicard and Forestier as long ago as 1921 remains popular. ${ }^{16}$ Air is still usually used for this purpose. It might also be considered whether the use of a stopcock to control air entry when syringes are exchanged (e.g. during the blood patch procedure) could reduce the frequency of this uncommon but not rare complication of epidural procedures.

\section{REFERENCES}

1. Krisanda TJ, Laucks SO. Pneumocephalus following an epidural blood patch procedure: an unusual cause of severe headache. Ann Emerg Med 1994;23(1):129-131.

2. Vasdev GM, Chantigian RC. Pneumocephalus following the treatment of a postdural puncture headache with an epidural saline infusion. J Clin Anesth 1994;6:508-511.

3. Headache Classification Committee of the International Headache Society. Classification and diagnostic criteria for headache disorders, cranial neuralgias, and facial pain. Cephalalgia 1988;8(Suppl 7):1-96.

4. González-Carrasco FJ, Aguilar JL, Llubiá C, Nogués S, VidalLópez F. Pneumocephalus after accidental dural puncture during epidural anesthesia. Reg Anesth 1993;18:193-195.

5. Lucas DN, Kennedy A, Dob DP. Dural puncture and iatrogenic pneumocephalus with subsequent transverse myelitis in a parturient. Can J Anesth 2000;47(11):1103-1106.

6. Hogan QH, Haddox JD. Headache from intracranial air after a lumbar epidural injection: subarachnoid or subdural? Reg Anesth1992;17:303-305.

7. Roderick L, Moore DC, Artru AA. Pneumocephalus with headache during spinal anesthesia. Anesthesiology 1985;62(5):690-692.

8. Dexter F, Reasoner DK. Theoretical assessment of normobaric oxygen therapy to treat pneumocephalus. Anesthesiology 1996;84(2):442-447.

9. Laviola S, Kiervelä M, Spoto M-R, Tschuor S, Alon E. Pneumocephalus with intense headache and unilateral pupillary dilatation after accidental dural puncture during epidural anesthesia for Cesarean section. Anesth Analg 1999;88:582-583.

10. Ruge JR, Cerullo LJ, McLone DG. Pneumocephalus in patients with CSF shunts. J Neurosurg 1985;63:532-536.

11. Labadie EL, Hamilton RH, Lundell DC, Bjelland JC. Hypoliquorreic headache and pneumocephalus caused by thoracosubarachnoid fistual. Neurology 1977;27:993-995.

12. Brown WH, Stothert JC. Traumatic subarachnoid-pleural fistula. J Trauma 1985;25(11):1105-1107.

13. Kiu M-C, Wan Y-L, Ng S-H, Lee S-T, Hao S-P. Pneumocephalus due to nasopharyngeal carcinoma: case report. Neuroradiology 1996;38:70-72.

14. Hayman LA, Carter K, Schiffman JS, Tang RA. A sellar misadventure - imaging considerations. Surv Ophthalmol 1996;42:252-254.

15. Maier W, Fradis M, Scheremet R. Spontaneous otogenic pneumocephalus. Ann Otol Rhinol Laryngol 1996;105:300-302.

16. Ash KM, Cannon JE, Biehl D. Pneumocephalus following attempted epidural anesthesia. Can J Anaesth 1991;38:772-774. 